Fu-Mei Lin · Chiu-Hsia Chiu · Tzu-Ming Pan

\title{
Fermentation of a milk-soymilk and Lycium chinense Miller mixture using a new isolate of Lactobacillus paracasei subsp. paracasei NTU101 and Bifidobacterium longum
}

Received: 16 March 2004 / Accepted: 25 September 2004 / Published online: 18 November 2004

(c) Society for Industrial Microbiology 2004

\begin{abstract}
A milk-soymilk mixture was fermented using Lactobacillus paracasei subsp. paracasei NTU101 and Bifidobacterium longum BCRC11847 at different inoculum ratios $(1: 1,1: 2,1: 5,2: 1$, and 5:1). When the inoculum ratio was $1: 2$, the cell numbers of both strains were balanced after $12 \mathrm{~h}$ of cultivation. The $\mathrm{pH}$ and titratable acidity were very similar at the various inoculum ratios of cultivation. The milk-soymilk mixture was supplemented with 5, 10, 15, and 20\% Lycium chinense Miller juice and fermented with Lactobacillus paracasei subsp. paracasei NTU101 and B. longum BCRC11847. Sensory evaluation results showed that supplementation with $5 \%$ Lycium chinense Miller juice improved the acceptability of the fermented milk-soymilk. The fermented beverage was stored at $4^{\circ} \mathrm{C}$ for 14 days; variations in $\mathrm{pH}$ and titratable acidity were slight. The cell numbers of L. paracasei subsp. paracasei NTU101 and B. longum BCRC11847 in the fermented beverage were maintained at $1.2 \times 10^{9} \mathrm{CFU} / \mathrm{ml}$ and $6.3 \times 10^{8} \mathrm{CFU} / \mathrm{ml}$, respectively, after 14 days of storage.
\end{abstract}

Keywords Lycium chinense Miller · Soymilk ·

Lactobacillus paracasei subsp. paracasei .

Bifidobacterium longum

\section{Introduction}

Soybean products such as soymilk, tofu, soybean cheese and miso are traditional foods in Asia; they are rich in protein, unsaturated fatty acids, lecithin and isoflavones, contain no cholesterol or lactose, and may be consumed

F.-M. Lin · C.-H. Chiu · T.-M. Pan ( $ه)$

Institute of Microbiology and Biochemistry,

National Taiwan University, 1, Sec. 4, Roosevelt Road,

Taipei, Taiwan, Republic of China

E-mail: tmpan@ntu.edu.tw

Tel.: + 886-2-23630231

Fax: + 886-2-23627044 by those suffering from lactose intolerance. Soymilk is also a suitable medium for growing lactic acid bacteria, thus improving the quality of fermented products. Similar to yogurt, fermented soymilk is called soyoghurt $[1,29,35]$, and soymilk has been recently used to partially replace milk in the production of yogurt-like products $[10,26]$.

The dried ripe fruit of Lycium chinense Miller has been widely used as an ingredient of herbal medicines and functional foods in traditional Chinese families. It contains $\beta$-carotene, ascorbic acid and tocopherols. The dried root bark of $L$. chinense Miller has been reported to contain phenolic amides, which have potent antioxidative activity and anti-fungal effects [14, 24]. Its leaves are said to be capable of preventing certain human diseases, such as arteriosclerosis, essential arterial hypertension, diabetes and night blindness [20]. The dried fruit of $L$. chinense Miller has also been reported to improve eyesight and fortify liver and kidney activities. Based on these health effects, and the sweetness and atractive red color it renders to products, $L$. chinense Miller was tested as a supplement to lactic-acid-bacteria-fermented milk-soymilk beverage in this study.

Lactic acid bacteria are currently being used in probiotic preparations, either singly or in combination. Lactobacillus, Streptococcus, and Bifidobacterium are the most commonly used in fermented dairy products $[9,11]$ since these bacteria comprise a portion of the desirable intestinal microflora [3] and have beneficial effects, including stimulation of the immune response [18, 34], anticarcinogenic activity $[16,25,37]$ and inhibition of the growth of pathogens $[2,4,8,15,17,31]$. There is a continuing need to improve existing starter cultures or to select new strains for use in specific fermentation processes when developing new products. The lactic acid bacteria from newborn infant feces were characterized and one of the isolates identified as Lactobacillus paracasei subsp. paracasei NTU101. This strain showed good survival at low $\mathrm{pH}$, tolerance against high bile concentration, and the ability to reduce serum cholesterol in vitro. 
A drawback to the use of soymilk is its unpleasant bean flavor, which is due to the presence of $n$-hexanal and pentanal, naturally present in soymilk as products of the breakdown of unsaturated acids [27]. The bean flavor and the presence in soymilk of indigestible oligosaccharides (such as raffinose and stachyose), which cause flatulence, have been responsible for low consumer acceptance. Bifidobacterium spp. can reduce the off-flavor of $n$-hexanal $[30,32]$ and ferment sucrose, raffinose and stachyose [7]. Furthermore, a significantly higher reduction in raffinose and stachyose content was found in soymilk fermented with mixed cultures of bifidobacteria and lactic acid bacteria than in those fermented with single lactic acid bacterium culture [36]. Thus, the aim of this work was to combine different percentages of milk, soymilk and $L$. chinense Miller juice with a mixed culture of Lactobacillus paracasei subsp. paracasei NTU101 and B. longum BCRC11847 in order to produce a new fermented lactic acid beverage.

\section{Materials and methods}

\section{Bacterial strains}

Lactobacillus paracasei subsp. paracasei NTU101 was isolated from infant feces in our laboratory. B. longum BCRC 11847, was obtained from the Biosource Collection and Research Center, the Food Industry Research and Development Institute (FIRDI), Hsinchu, Taiwan.

Preparation of milk and soymilk

Milk was $8 \%(\mathrm{w} / \mathrm{v})$ reconstituted skim milk powder. Soymilk was prepared following the method of Chou and Hou [5]. Whole soybeans were washed and soaked overnight in distilled water. After decanting the water, the soaked soybeans were mixed with ten times their weight in distilled water and placed in a blender for $3 \mathrm{~min}$. The resultant slurry was filtered through doublelayered cheesecloth to obtain soymilk. The milk and the soymilk were heat-treated individually in water baths at $90^{\circ} \mathrm{C}$ for $1 \mathrm{~h}$. After heat treatment and cooling to room temperature, they were mixed at a proportion of $25 \%$ milk and $75 \%$ soymilk.

\section{Ratio of mix-culture strains}

The strains were cultivated in MRS broth (Difco, Detroit, Mich., USA) and then subcultured in skim milk at $30^{\circ} \mathrm{C}$ for $16 \mathrm{~h}$; this served as the inoculum. The inoculum ratios of Lactobacillus paracasei subsp. paracasei NTU101 and B. longum BCRC11847 were at 1:1, 1:2, $1: 5,2: 1$, and $5: 1(\mathrm{v} / \mathrm{v})$, respectively, for the fermented $25 \%$ milk and $75 \%$ soymilk combinations. The final inoculum volume was $3 \%(\mathrm{v} / \mathrm{v})$.
Ratio of L. chinense Miller juice to milk-soymilk

Lycium chinense Miller was washed and mixed with five times its weight in distilled water and blended for $3 \mathrm{~min}$. The resultant slurry was filtered through a sieve (juice contains pulp) and then heated in a water bath at $90^{\circ} \mathrm{C}$ for $1 \mathrm{~h}$. After heat treatment and cooling to room temperature, L. chinense Miller juice was added to the milksoymilk mixtures at the rate of $5,10,15$, and $20 \%$, respectively.

\section{Batch fermentation and analytical assays}

Lactobacillus paracasei subsp. paracasei NTU101 and B. longum BCRC11847 were cultivated in $100 \mathrm{ml}$ of sterilized milk-soymilk with different amounts of $L$. chinense Miller juice at $30^{\circ} \mathrm{C}$ for $12 \mathrm{~h}$. During incubation, samples were taken at $0,2,4,6,8,10$, and $12 \mathrm{~h}$ for testing of $\mathrm{pH}$, culture growth and titratable acidity. The $\mathrm{pH}$ of the sample was measured with a $\mathrm{pH}$ meter (MP2000, Mettler Toledo, Greifensee, Switzerland). MRS agar (Difco, Detroit, Mich., USA) was used to enumerate $L$. paracase $i$ subsp. paracasei NTU101 and $B$. longum BCRC11847. Plates were incubated in an ordinary incubator at $37^{\circ} \mathrm{C}$ for 2 days. The colonies (the morphologies of two strains differed) that appeared on the plates were then counted. Titratable acidity, expressed as a percentage of lactic acid by weight, was measured by titration with $0.1 \mathrm{~N} \mathrm{NaOH}$.

\section{Sensory evaluation}

The milk-soymilk mixtures were supplemented with 5 , 10,15 , and $20 \%$ L. chinense Miller juice and fermented with $L$. paracasei subsp. paracasei NTU101 and B. longum $\mathrm{BCRC} 11847$ at $30^{\circ} \mathrm{C}$ for $8 \mathrm{~h}$. The organoleptic properties of the fermented products were then evaluated. Sensory evaluation was carried out after $24 \mathrm{~h}$ storage at $4^{\circ} \mathrm{C}$. Samples (ca. 5\% sugar) were served at about $4^{\circ} \mathrm{C}$ and were scored on a $1-9$ hedonic scale (nine being considered excellent, five acceptable, and one extremely poor). A panel of 32 untrained students evaluated each sample. The characteristics evaluated included color, flavor, taste, texture and overall acceptability. Fermented milk-soymilk beverage, with no L. chinense Miller juice added, was used as the control. The other samples were compared with the control, evaluated and scored. Duncan's multiple range tests were used to determine significant differences.

\section{Shelf-life studies}

The shelf-life of the sample with the highest mean score of overall acceptability was assessed. The fermented beverage was stored at $4^{\circ} \mathrm{C}$ for 14 days, and then evaluated for $\mathrm{pH}$, culture viability and titratable acidity. 


\section{Results and discussion}

Effect of different ratios of mixed culture strains

Bifidobacterium spp. can reduce the off-flavor of $n$-hexanal and fermented sucrose, raffinose and stachyose. For this reason, it was used as the starter culture for fermenting soymilk, in order to increase its acceptability. Different inoculum ratios $(1: 1,1: 2,1: 5,2: 1$, and 5:1) of Lactobacillus paracasei subsp. paracasei NTU101 and $B$. longum were used to ferment the milk-soymilk mixture.

As shown in Fig. 1, Lactobacillus paracasei subsp. paracasei NTU101 reached higher cell numbers than

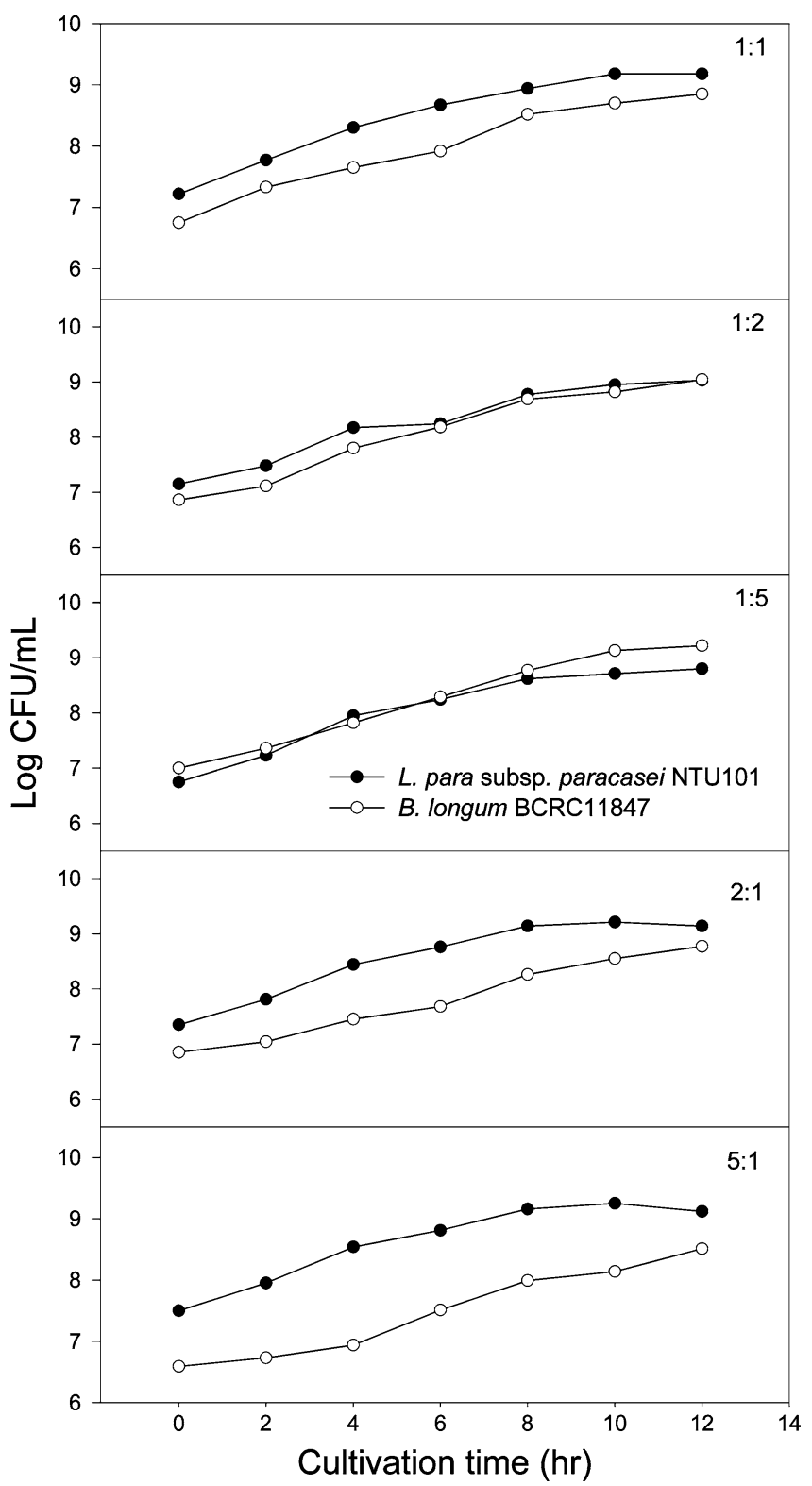

Fig. 1 Cell numbers of different inoculum ratios of Lactobacillus paracasei subsp. paracasei NTU101 and Bifidobacterium longum BCRC11847 in $25 \%$ milk and $75 \%$ soymilk
B. longum, except for the inoculum ratio at $1: 5$, but its presence did not influence the development of $B$. longum in the milk-soymilk. At inoculum ratios of Lactobacillus paracasei subsp. paracasei NTU101 and $B$. longum were of $1: 2$ and 1:5, the cell numbers of both strains were about the same. The cell number of $B$. longum was higher than that of $L$. paracasei subsp. paracasei NTU101 after $12 \mathrm{~h}$ of cultivation at an inoculum ratio at 1:5. At an inoculum ratio of $1: 2$, the cell numbers of both strains were balanced after $12 \mathrm{~h}$ of cultivation. A good balance of these two species is desirable in fermented beverages, since both are associated with beneficial effects [21]. As such, the ratio of 1:2 (L. paracasei subsp. paracasei NTU101: B. longum) was used in subsequent studies. By contrast, at the different inoculum ratios of cultivation, the $\mathrm{pH}$ and titratable acidity were very similar (Fig. 2). This result concurs with the report of Macedo et al. [26], indicating that, in spite of the difference in the number of viable cells, the $\mathrm{pH}$ and titratable acidity of all the beverages were very similar.

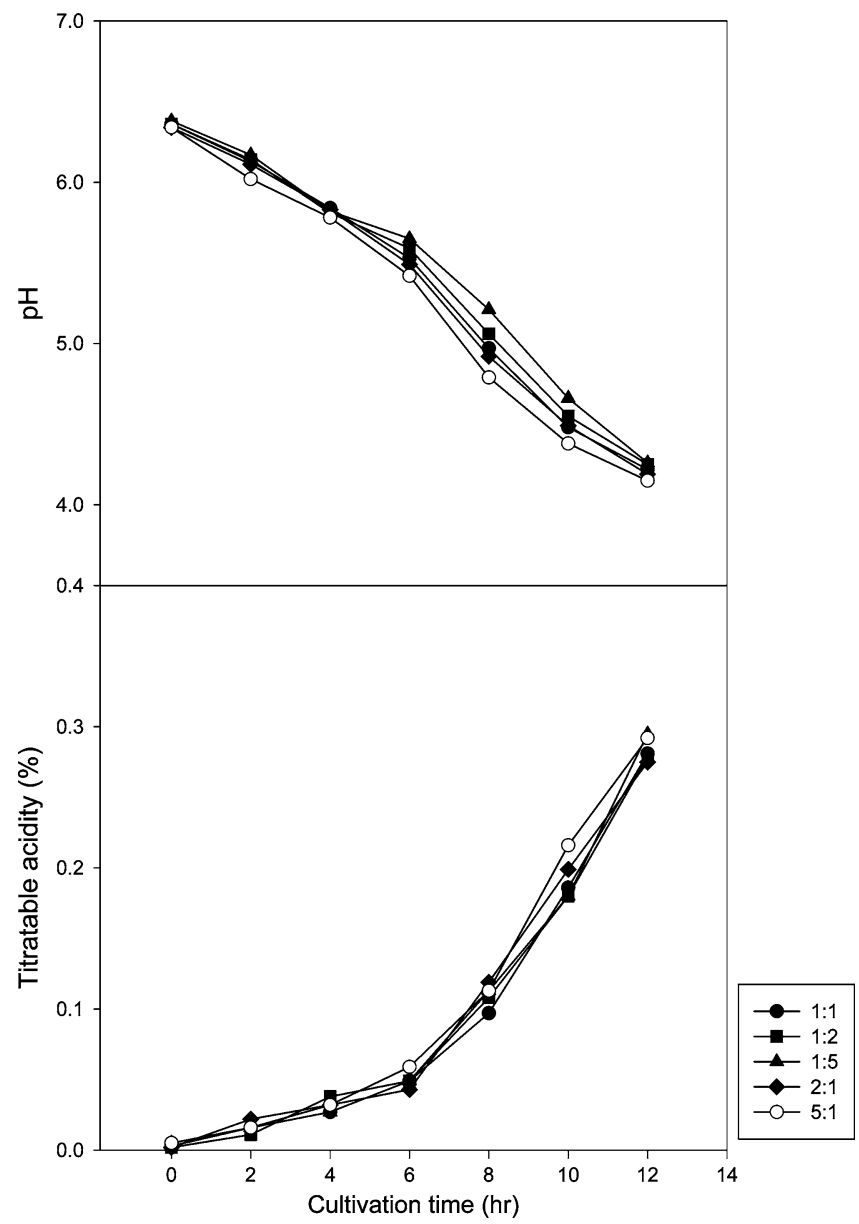

Fig. 2 Titratable acidity and $\mathrm{pH}$ of different inoculum ratios of L. paracasei subsp. paracasei NTU101 and B. longum BCRC 11847 in $25 \%$ milk and $75 \%$ soymilk 
Effect of different ratios of $L$. chinense Miller juice to milk-soymilk

The combination of $25 \%$ milk and $75 \%$ soymilk was supplemented with 5, 10,15 and 20\% L. chinense Miller juice and then fermented. The results are shown in Fig. 3. Supplementation with different amounts of L. chinense Miller juice did not affect the growth of Lactobacillus paracasei subsp. paracasei NTU101 or $B$. longum (in the inoculum ratio of 1:2); the cell numbers for both Lactobacillus paracasei subsp. paracasei NTU101 and B. longum were about the same. The $\mathrm{pH}$ levels of the fermented beverages supplemented with 10 , 15 , and $20 \%$ L. chinense Miller juice were all below 4.0. The titratable acidity of the milk-soymilk mixture supplemented with $L$. chinense Miller juice was higher than that without added L. chinense Miller juice.

\section{Sensory evaluation}

The results of the sensory evaluation are shown in Table 1. The mean score for the color of the fermented beverage supplemented with 5\% L. chinense Miller juice

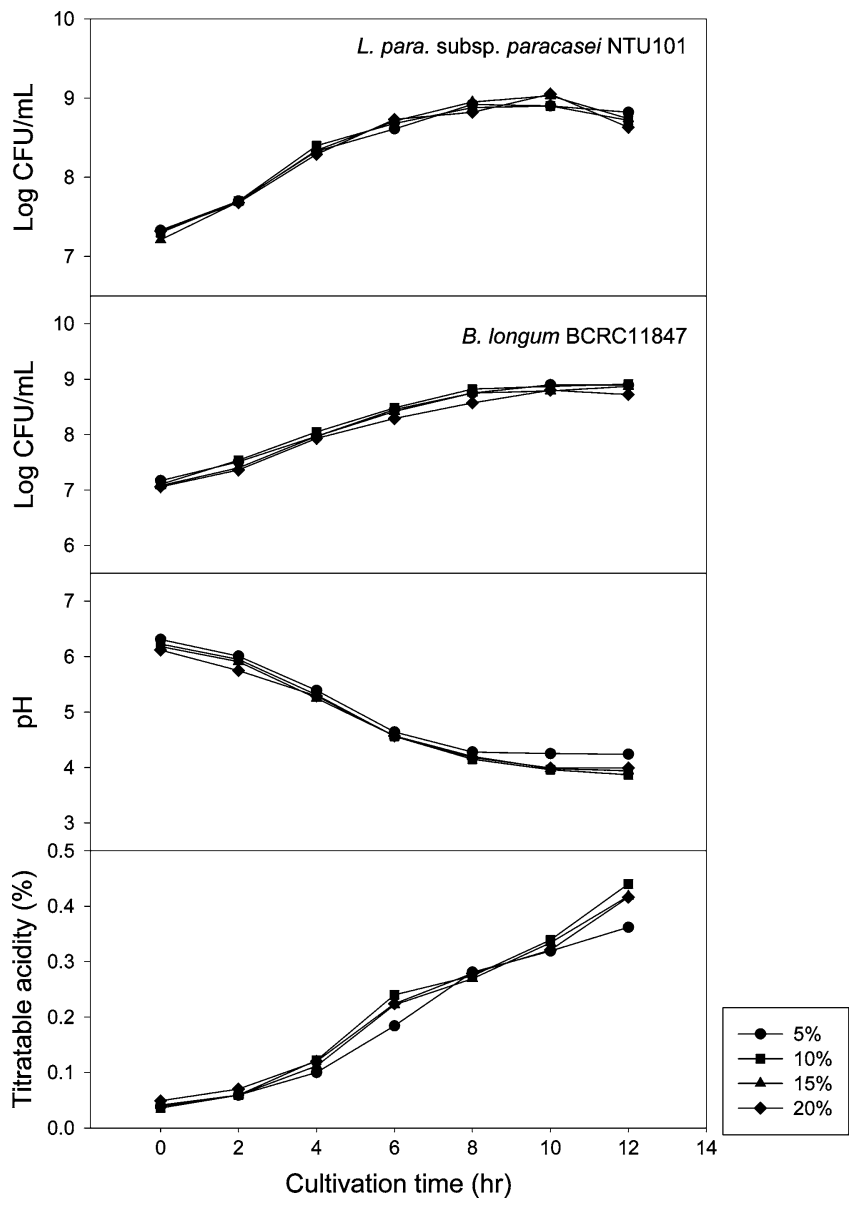

Fig. 3 Growth of culture mix in $25 \%$ milk and $75 \%$ soymilk supplemented with different amounts of $L$. chinense Miller juice
Table 1 Average scores for the sensory properties of different fermented soymilks. Control Milk-soymilk mixture with no added L. chinense Miller juice; 5, 10, 15, 20 milk-soymilk mixture supplemented with 5, 10, 15, and 20\% L. chinense Miller juice, respectively. Numbers with a different letter superscript were significantly different $(5 \%$ probability) from each other

\begin{tabular}{llllll}
\hline Characteristics & \multicolumn{5}{l}{ Sample } \\
\cline { 2 - 6 } & Control & 5 & 10 & 15 & 20 \\
\hline Color & $5.0^{\mathrm{b}}$ & $5.8^{\mathrm{a}}$ & $5.5^{\mathrm{a}, \mathrm{b}}$ & $5.2^{\mathrm{a}, \mathrm{b}}$ & $3.8^{\mathrm{c}}$ \\
Flavor & $5.0^{\mathrm{a}}$ & $4.9^{\mathrm{a}}$ & $5.4^{\mathrm{a}}$ & $5.2^{\mathrm{a}}$ & $5.2^{\mathrm{a}}$ \\
Taste & $5.0^{\mathrm{a}}$ & $4.9^{\mathrm{a}}$ & $5.4^{\mathrm{a}}$ & $5.2^{\mathrm{a}}$ & $5.3^{\mathrm{a}}$ \\
Texture & $5.0^{\mathrm{a}, \mathrm{b}}$ & $5.3^{\mathrm{a}}$ & $5.4^{\mathrm{a}}$ & $5.2^{\mathrm{a}, \mathrm{b}}$ & $4.6^{\mathrm{b}}$ \\
Overall acceptability & $5.0^{\mathrm{b}}$ & $5.9^{\mathrm{a}}$ & $5.0^{\mathrm{b}}$ & $5.0^{\mathrm{b}}$ & $4.8^{\mathrm{b}}$ \\
\hline
\end{tabular}

was higher than that of the other samples, and significantly different from both the control and the fermented beverage supplemented with $20 \%$ L. chinense Miller juice. Supplementation with $5 \%$ L. chinense Miller juice improved the color of the beverage. Although the flavor and taste scores of the beverage supplemented with $5 \%$ L. chinense Miller juice were lowest, and highest for the beverage supplemented with $10 \% L$. chinense Miller juice, there were no significant differences between any of the samples. The flavor and taste scores for all samples were almost the same. The mean scores for the texture of the fermented beverages supplemented with 5 and $10 \%$ L. chinense Miller juice were significantly higher than those for samples supplemented with $20 \%$ L. chinense Miller juice. In overall acceptability, the fermented beverage supplemented with $5 \%$ L. chinense Miller juice had the highest mean scores; this was significantly different from all other samples. As shown from the results, supplementation with $5 \%$ L. chinense Miller juice can improve the acceptability of a fermented beverage made from a combination of $25 \%$ milk and $75 \%$ soymilk.

\section{Shelf-life studies}

Changes in viable cells and $\mathrm{pH}$ levels of fermented products have been found to be related to storage time, temperature, hydrogen peroxide content, oxygen content, initial number of strains and the kinds of strains used [6, 28]. For example, Chou and Hou [5] reported that the cell numbers and $\mathrm{pH}$ level of Bifidobacterium infantis, in fermented soymilk were lower when stored at $25^{\circ} \mathrm{C}$ than at $5^{\circ} \mathrm{C}$. On the other hand, when Garro et al. [12] fermented soymilk with several single strains, it was found that, during storage at $4^{\circ} \mathrm{C}$, the stability of the microflora differed markedly among the starter cultures. Therefore, both the starter used for fermentation and the storage conditions are very important to the quality of fermented beverages. As shown in Fig. 4, after 6 days of storage, the cell numbers of L. paracasei subsp. paracasei NTU101 and B. longum had increased slightly. The reason may be that the fermented beverage was sweetened with 5\% sugar, which had been used as a 


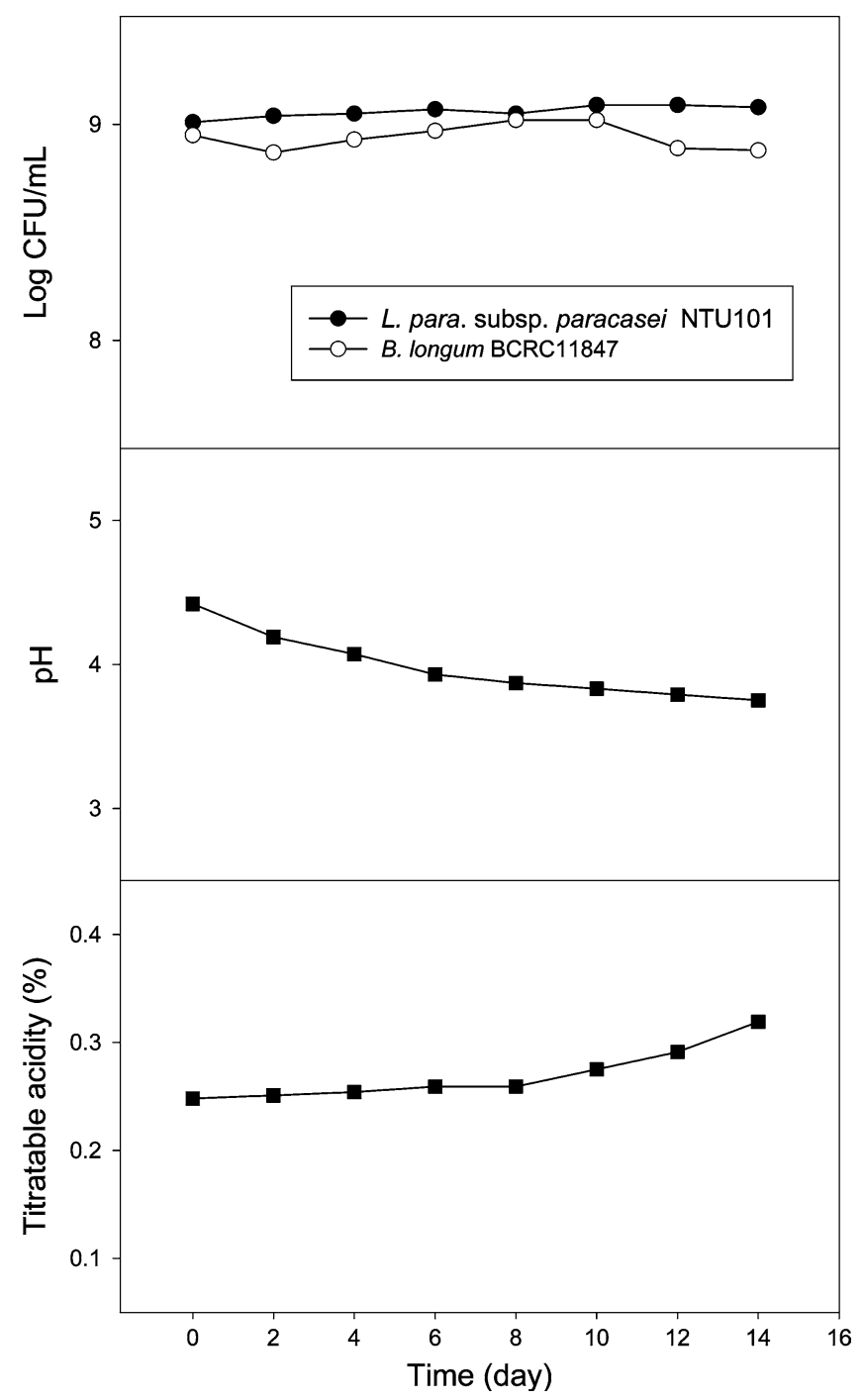

Fig. 4 Variation in cell numbers, $\mathrm{pH}$ and titratable acidity in the fermented beverage during storage

source of carbon for strain growth. After 10 days of storage, the cell numbers of $B$. longum had decreased, reaching $6.3 \times 10^{8} \mathrm{CFU} / \mathrm{ml}$ on the 14 th day. A variation in cell numbers of L. paracase $i$ subsp. paracasei NTU101 was not apparent. After 12 days of storage, the cell numbers of $L$. paracasei subsp. paracasei NTU101 had slightly decreased and remained at $1.2 \times 10^{9} \mathrm{CFU} / \mathrm{ml}$ at the end of the storage period. The cell numbers of the yogurt organism initially increased after manufacture, decreasing during a long storage period $[13,22,26]$. In this study, the decrease in the cell numbers of $B$. longum was more significant than that of $L$. paracasei subsp. paracasei NTU101. Lankaputhra et al. [23] reported that at a $\mathrm{pH}$ below 4.3, bifidobacteria survival was greatly affected. It has been suggested that, in order to have a therapeutic effect, the minimum number of probiotics in a product should be above $10^{5}$ or $10^{6} \mathrm{CFU} / \mathrm{g}[19,33]$. Medina and Jordano [28] also reported that a highquality fermented beverage should contain $1 \times 10^{6}-$ $1 \times 10^{8} \mathrm{CFU}$ probiotics $/ \mathrm{ml}$. After 14 days of storage, the cell numbers of $L$. paracasei subsp. paracasei NTU101 and $B$. longum in the fermented beverage in this study were $1.2 \times 10^{9}$ and $6.3 \times 10^{8} \mathrm{CFU} / \mathrm{ml}$, respectively. The variation in $\mathrm{pH}$ and titratable acidity were slight and may have been due to the buffering effect of solids (soy proteins, sugar) in the fermented beverage [26]. After 14 days of storage, the titratable acidity had increased slightly. During the storage period, syneresis did not occur.

\section{Conclusion}

In this study, a fermented beverage was produced with a combination of milk, soymilk and L. chinense Miller juice. It was fermented using a culture mix of Lactobacillus paracasei. subsp. paracasei NTU101 and B. longum. According to the sensory evaluation results, supplementation with $5 \%$ L. chinense Miller juice was found to improve the acceptability of the fermented milk and soymilk combinations. The variations in cell numbers, $\mathrm{pH}$ levels and titratable acidity of the products were slight and syneresis was not observed. The quality of this product would, therefore, be retained during storage and could be applied to dietary adjuncts.

Acknowledgements This study was sponsored by the National Science Council of Taiwan, ROC (Project No. NSC 92-2313-B-002077). We gratefully acknowledge the assistance of Dr. S. Chen in sensory evaluation.

\section{References}

1. Angeles AG, Marth EH (1971) Growth and activity of lactic acid bacteria in soymilk. I. Growth and acid production. J Milk Food Technol 34:30-36

2. Ashenafi M (1991) Growth of Listeria monocytogenes in fermenting tempeh made of various beans and its inhibition by Lactobacillus plantarum. Food Microbiol 8:303-310

3. Berg RD (1998) Probiotics, prebiotics or 'conbiotics'. Trends Microbiol 6:89-92

4. Chateau N, Castellanos I, Deschamps AM (1993) Distribution of pathogen inhibition in the Lactobacillus isolates of a commercial probiotic consortium. J Appl Bacteriol 74:36-40

5. Chou CC, Hou JW (2000) Growth of bifidobacteria in soymilk and their survival in the fermented soymilk drink during storage. Int J Food Microbiol 56:113-121

6. Dave RI, Shah NP (1998) Ingredient supplementation effects on viability of probiotic bacteria in yogurt. J Dairy Sci 81:2804-2816

7. Desjardins ML, Roy D, Goulet J (1990) Growth of bifidobacteria and their enzyme profiles. J Dairy Sci 73:299-307

8. Drago L, Gismondo MR, Lombardi A, de Haën C, Gozzini L (1997) Inhibition of in vitro growth of enteropathogens by new Lactobacillus isolates of human intestinal origin. FEMS Microbiol Lett 153:455-463

9. Dunne C, Murphy L, Flynn S, O’Mahony L, O’Halloran S, Feeney M, Morrisey D, Thornton G, Fitzgerald G, Daly C, Kiely B, Quigley EMM, O'Sullivan GC, Shanahan F, Collins JK (1999) Probiotics : from myth to reality. Demonstration of functionality in animal models of disease and in human clinical trials. Antonie van Leeuwenhoek 76:279-292 
10. Fang TJ, Yang CYS (1992) Effects of yogurts partially replaced by soymilk on growth kinetics of lactic acid bacteria, acid production, and the sensory properties of final products. Food Sci 19:253-263

11. Fooks LJ, Fuller R, Gibson GR (1999) Prebiotics, probiotics and human gut microbiology. Int Dairy J 9:53-61

12. Garro MS, Valdez GF, Oliver G, Giori GS (1999) Starter culture activity in refrigerated fermented soymilk. J Food Prot 62:808-810

13. Hamann WIT, Marth EH (1984) Survival of Streptococcus thermophilus and Lactobacillus bulgaricus in commercial and experimental yogurts. J Food Port 47:781-786

14. Han SH, Lee HH, Lee IS, Moon YH, Woo ER (2002) A new phenolic amide from $L$. chinense Miller. Arch Pharm Res $25: 433-437$

15. Harris LJ, Daechsel MA, Stiles ME, Klaenhammer TR (1989) Antimicrobial activity of lactic acid bacteria against Listeria monocytogenes. J Food Port 52:384-387

16. Hirayama K, Rafter J (2000) The role of probiotic bacteria in cancer prevention. Microbes Infect 2:681-686

17. Hudault S, Lievin V, Bernet-Camard MF, Servin AL (1997) Antagonistic activity exerted in vitro and in vivo by Lactobacillus casei (strain GG) against Salmonella typhimurium C5 infection. Appl Environ Microbiol 63:513-518

18. Isolauri E, Sütas $Y$, Kankaanpää $P$, Arvilommi H, Salminen $S$ (2001) Probiotics: effects on immunity. Am J Clin Nutr $73: 444 \mathrm{~s}-450 \mathrm{~s}$

19. Kim HS (1988) Characterization of lactobacilli and bifidobacteria as applied to dietary adjuncts. Cult Dairy Prod J 23:6-9

20. Kim SY, Lee KH, Chang KS, Bock JY, Jung MY (1996) Taste and flavor compounds in box thorn (L. chinense Miller) leaves. Food Chemistry 58:297-303

21. Klaver FAM, Kingma F, Weerkamp AH (1993) Growth and survival of bifidobacteria in milk. Neth Milk Dairy J 27:151164

22. Kneifel W, Doris J, Erhard F (1993) Microflora and acidification properties of yogurt and yogurt-related products fermented with commercially available starter cultures. Int J Food Microbiol 18:179-189

23. Lankaputhra WEV, Shah NP, Britz ML (1996) Survival of bifidobacteria during refrigerated storage in the presence of acid and hydrogen peroxide. Milchwissenschaft 51:65-70
24. Lee DG, Park Y, Kim MR, Jung HJ, Seu YB, Hahm KS, Woo ER (2004) Anti-fungal effects of phenolic amides isolated from the root bark of L. chinense. Biotechnol Lett 26:1125-1130

25. Lee YK, Salminen S (1995) The coming of age of probiotics. Trends Food Sci Technol 61:241-244

26. Macedo RF, Renato K, Freitas RJS, Pandey A, Soccol CR (1999) Production and shelf-life studies of low cost beverage with soymilk, buffalo cheese whey and cow milk fermented by mixed cultures of Lactobacillus casei ssp. shirota and Bifidobacterium adolescentis. J Basic Microbiol 39:243-251

27. Matoba T, Hidaka T, Narita H, Kitmura K, Keizuma N, Kito M (1985) Lipoxygenase-2-isozyme is responsible for generation of $n$-hexanal in soybean homogenate. J Agric Food Chem $33: 856-860$

28. Medina LM, Jordano R (1994) Survival of constitutive microflora in commercially fermented milk containing bifidobacteria during refrigerated storage. J Food Prot 56:731-733

29. Mital BK, Steinberg MP, Nelson AI, Hymowitz T (1975) Utilization of oligosaccharides by lactic acid bacteria during fermentation of soymilk. J Food Sci 40:114-118

30. Murti TW, Bouillanne C, Landon M, Desmazeaud MJ (1992) Bacterial growth and volatile compounds in yoghurt-type products from soymilk containing Bifidobacterium sp. J Food Sci 1:153-157

31. Reid G (1999) The scientific basis for probiotic strains of Lactobacillus. Appl Environ Microbiol 65:3763-3766

32. Scalabrini P, Rossi M, Spettoli P, Matteuzzi D (1998) Characterization of Bifidobacterium strains for use in soymilk fermentation. Int J Food Microbiol 39:213-219

33. Schillinger U (1999) Isolation and identification of lactobacilli from novel-type probiotic and mild yoghurts and their stability during refrigerated storage. Int J Food Microbiol 47:79-87

34. Tannock GW (1998) Studies on the intestinal microflora: a prerequisite or the development of probiotics. Int Dairy J 8:527-534

35. Wang HL, Kraidej L, Hesseltine CW (1974) Lactic acid fermentation of soy bean milk. J Milk Food Technol 37:71-73

36. Wang YC, Yu RC, Yang HY, Chou CC (2003) Sugar and acid contents in soymilk fermented with lactic acid bacteria alone or simultaneously with bifidobacteria. Food Microbiol 20:333-338

37. Wollowski I, Rechkemmer G, Pool-Zobel BL (2001) Protective role of probiotics and prebiotics in colon cancer. Am J Clin Nutr 73:451-455 